\title{
Challenges in Civil Aviation for the New Brazilian
}

\section{Government}

\author{
Flademir Cândido da Silva \\ Department of Law, State University of Londrina, Paraná, 86057-970, Brazil
}

\begin{abstract}
After a cycle of management that began with President Luis Inácio Lula da Silva, the inauguration of Jair Bolsonaro bringing a new period of management in the Federative Republic of Brazil. In addition to macroeconomic issues and various other national interests, the new government will have to analyze the legacies and will have new challenges in the civil aviation sector. Using an evolutionary historical perspective, this article briefly points out some alternatives for the implementation of viable projects for the development of this important sector for the country's development.
\end{abstract}

Key words: Aviation planning, air navigation, ATC (air traffic control).

\section{Introduction}

One of the recurring problems in the succession of rulers in Brazil has been the lack of continuity of the initiated projects, as well as the absence of sustainable planning and legal security. However, despite the political and legal insecurities experienced in recent years, the tendency is for the new government to show a reasonable predictability of a new management period. At first, a term of four years is expected, but that time may be extended in favor of the country, the basis for an intersectoral cross-governmental and long-term planning.

This paper lists some projects initiated in recent years that have not been completed and, therefore, will require appreciation by the new Brazilian government that took office in 2019. The future treatment of issues listed here may even be archiving, since the new President of the Republic may establish new understandings and priorities; however, an analysis of the historical context in which these subjects are inserted will be necessary, as well as a way forward which is compatible with the new policy guidelines

\footnotetext{
Corresponding author: Flademir Cândido da Silva, master in law, research field: aviation law. E-mail: flademir_silva@uol.com.br.
}

and the changing international scenario.

\section{Government Aviation Management Structure}

Government management of Civil Aviation has undergone several adjustments, such as leaving the domain of the now extinct Ministry of Aeronautics, when the military controlled all branches of this sector. With the creation of the Ministry of Defense in 1999, the Air Force was relegated to a military command, while preserving the entire control over aviation. Only in 2005, ANAC (National Civil Aviation Agency) was created in order to replace the DAC (Department of Civil Aviation) [1].

In 2011, with the end of CONAC (National Civil Aviation Council), SAC (Secretariat of Civil Aviation) acquired status of ministry and among its attributions were the planning for the aviation sector, the coordination of infrastructure development funds and the coordination of the bodies and entities of the Brazilian civil aviation system, such as ANAC and Infraero (Brazilian Company for Airport Infrastructure), in conjunction with the Aeronautical Command, which holds control over air navigation services and aeronautical investigations.

The SAC's ministerial status lasted until May 12, 
2016, when, after leaving the position of interim, President Michel Temer made a ministerial adjustment and SAC became a section of the Ministry of Transport, Ports and Civil Aviation. Temer's government kept among its main advisors the former chairmen of Civil Aviation authorities (Eliseu Padilha and Moreira Franco), although in other ministerial positions. In practice, the protagonism of these leaders did not serve to guarantee the continuity of the projects initiated in Civil Aviation.

One of the first activities of the new President was to choose his main advisors and define the extent of competence of the ministries. The Ministry of Infrastructure was created and it corporated the former Ministry of Transport and Mr. Tarcisio de Freitas, a manager who has been working since the government of Dilma Roussef, was chosen to be the chairmen of this department [2].

\section{Airport Model}

The federal program for airport concessions began with the auction of the airport of Sao Gonçalo do Amarante, RN, in 2011. The following airports were auctioned in 2012: Brasilia/DF, Guarulhos and Viracopos, in Sao Paulo; and, in 2013, the International Airports of Rio de Janeiro and Minas Gerais (Confins). Such concessions aimed at improving the quality of services of these airports and accelerating the execution of the work required to meet the demand for air transport to major events, such as the World Cup in 2014 and the Olympics in June 2016. In 2017, four airports were granted: Fortaleza/CE; Salvador/BA; Florianopolis/SC; and Porto Alegre/RS.

The fifth round of airport concessions is scheduled for March, 2019, with 12 airports to be auctioned in three regional blocks. The Northeast block is formed by the airports of Recife/PE, Maceio/AL, Aracaju/SE, Joao Pessoa/PB, Campina Grande/PB and Juazeiro do Norte/CE. Another block is the Midwest, with the concession of the airports of Cuiabá/MT, Sinop/MT, Rondonópolis/MT and Alta Floresta/MT. Finally, in the southeast block are the airports of Vitória/ES and Macaé/RJ [3].

The expectation expressed by the new Minister of Infrastructure, when he took office on January 3, 2019, is that the fifth round of concession blocks will be successful and, therefore, the government will announce new rounds to concede all airports from the Infraero network, including the central airports of Rio de Janeiro (Santos Dumont) and São Paulo (Congonhas) [2].

From a financial point of view, most of the concessionaires of the first granted airports face difficulties not only due to the crisis that affected air travel, but also because of the investigations of operation Lava Jato (Jet wash in Portuguese), since the first dealerships controlling groups were led by contractors involved in criminal investigations [4].

On the other hand, Infraero saw its revenue cut by more than $50 \%$ without a corresponding reduction in costs. As the state-owned company which administers a net of airports, its financial sustainability has been questioned in a system of cross subsidies (the surplus compensates the deficit), although it is still recognized that several deficit airports are essential for national integration. The State is yet to receive $49 \%$ of divedens in SPE (Special Purpose Entities) from the first concessions [4].

In 2017, the Federal Government announced the interest in the sale of Infraero's share in the concessionaires of Rio de Janeiro, Brasília, Belo Horizonte and Guarulhos airports, in which it holds $49 \%$ of the capital, as well as a proposal for regulation of certain concessions problems. However, at the time this paper was written, none of these measures had been implemented and the financial situation of Infraero and the first concessionaires are being questioned. Incidentally, the Viracopos Concessionaire has entered a process of judicial recovery and awaits a solution for reverting the concession.

The experimentalism of airport concessions took the monopoly of Infraero, but resulted in fragmented forms 
of concession that require harmonization. The possibilities for the Brazilian airport model are broad and will depend on the profile of the new government, which should focus on the sustainability of the entire system. At the beginning of this government, the choices of President Jair Bolsonaro show a liberal policy that seeks attraction of foreign investments.

\section{Regional Aviation}

In order to expand the development of the national civil aviation system from the 90s, a program, PROFAA (Federal Program of Aid for Airports), was established with modest resources that were not well engaged. In 2011, it was established with the SAC (Civil Aviation Secretary), the robust FNAC (National Civil Aviation Fund), with assets granted by the concessions. Thus, in a complementary way, in December 2012, it was announced the PDAR (Regional Aviation Program), aiming at increasing the number of frequencies on regional routes and the number of cities served by scheduled air transport, especially for the country's less developed regions. As the idea was to provide $96 \%$ of the population with a passenger terminal at a maximum distance of $100 \mathrm{~km}$, the goal of the SAC was to invest about R $\$ 7.3$ billion in the construction or renovation of 270 airports.

Based on three pillars (airport infrastructure, management and subsidies), the PDAR Act pending in the National Congress as Provisional Measure 656/14, provides subsidies for the occupancy of up to 60 passenger aircraft across the country (except for the Amazon Region), or subsidies on fares and routes at airports with annual turnover of up to 600 thousand passengers (up to 800,000 in the Amazon Region). However, the Act still awaits Executive regulation for the subsidies to be offered.

On the other hand, the COMARA (Airports of the Amazon Region Committee), a unit of the FAB (Brazilian Air Force), which has operated for 63 years and has performed more than 182 construction projects in remote regions of the Amazon, has faced difficulties in integrating missions. In a meeting with the Foreign Relations and National Defense Committee of the Chamber of Deputies, on 05/17/2017, the Air Force Commander clarified that the aeronautics had contingent funds that affected the maintenance of airports in the Amazon States (Acre, Rondônia, Amazonas, Pará, Roraima) [5].

In the short period in which the SAC had ministerial status from 2011 to 2016 , there was a reduction in the number of cities assisted by regular commercial aviation. The number of cities served by scheduled flights fell from 180 to 122 ; in $33 \%$ of these assisted cities, there is no competition between airlines. A country with the territorial dimension that Brazil has cannot do without integrating its several regions by air transport [6].

In addition to the PDAR regulation, it is important to resolve the issue of loans from FNAC resources, with funds also sufficient to revitalize COMARA. However, in addition to public funding, the regional aviation requires partnerships with the private sector and a more open policy for new airlines.

\section{Opening to Foreign Capital in Airlines}

The air transport market which was consolidated after the end of the 2nd World War, was based on a protective structure. Article 7 of the Chicago Convention of 1944 established that each State would exercise exclusively the operation of air transport within its borders (cabotage); and on international routes, the granting of traffic rights would be through reciprocal agreements between two States, with the guarantee that their nationals would have substantial ownership and effective control over the designated airlines. Thus, the Brazilian Aeronautics Code (CBA, Law No. 7,565/1986), restricted domestic transport to Brazilian companies (art. 216). And in order to meet the criteria of substantial ownership and effective control, a national airline, besides being run by Brazilians, could not have foreign capital participation in a percentage greater than $20 \%$ of the voting capital 
(article 181 and 182, II. CBA).

In recent decades, both at global and national levels, the rules on nationality of the companies have been relaxed. With the proliferation of regional, plurilateral and multilateral agreements, further foreign investments were attracted and the criteria for defining a national company, in various countries, no longer limited foreign capital. In this way, especially in developing countries, there is an international competition to attract foreign investment, enabling that new airlines be established in home markets [7].

In Brazil, since the Constitutional Amendment No. $6 / 1995$, discrimination against companies founded on the origin of capital has fallen, except for rare cases specified in the Major Law (airline is no exception). If the company is incorporated in Brazil and subject to national laws, the origin of its capital is irrelevant. Discrimination would be possible only in cases specified in the Constitution itself, as for example newspaper and radio, sound and image broadcasting companies, which have special treatment according to Article 222 of the Constitution.

Part of the resistance is due to confusion about the constitutional concept of national company without restriction to foreign capital for fear of giving away the domestic air transport (cabotage) to foreign airlines. These are different things, although this more liberal issue of cabotage regarding foreign companies deserves to be discussed as well, considering the gradual openness that should occur with respect to regional air integration agreements in South America. As examples of agreements signed by Brazil in the region, there is the Fortaleza Agreement of 1996 and Open Skies Multilateral Agreement for member states of CLAC (Latin American Comission for Civil Aviation) suggested in 2010 [8].

Thus, the limitation of foreign capital to an airline established in the CBA does not make sense, but as the removal of this limit is not made explicit, several proposals for laws have already appeared that have not yet been resolved. However, in its last month in office, the Temer Government issued a MP (provisional measure), a law that needs to be ratified by Congress to acquire permanent validity, in order to remove the restriction on foreign capital for airlines. Thus, the MP No. 863/2018, which complies with the new government policy tends to expand investments in airlines.

\section{Air Navigation Subsector}

The organizational model of air traffic control in Brazil is unique in the world, it is marked by the use of an infrastructure integrated to meet military defense requirements and air traffic services. The air defense and air traffic control system is composed by four integrated centers, CINDACTAS I, II, III and IV, respectively, located in the cities of Brasilia, Curitiba, Recife and Manaus. DECEA is the central body of the Airspace Control System (SISCEAB), which acts as both a regulator and an air navigation service provider, an activity that includes stations that provide air navigation services in several airports in the country.

Infraero, since the incorporation of TASA (former civil provider of air navigation services) in 1996, also provides air navigation services at several airports. In addition to the State, there are some private companies also classified as EPTA (Telecommunication and Air Traffic Services Provider Station) that are authorized to provide air navigation services in medium and small airports [9].

There are no objective criteria that define the relationship between airport service providers and air navigation service providers at Brazilian airports. There are cases where Airports are managed by Infraero and towers by the military DECEA; there are airports administered by state agencies with Infraero EPTAs (Bauru, Presidente Prudente, for example); and there are airports with EPTAs administed by a concessionaire (São Gonçalo do Amarante-RN), with services provided by the military (Confins, Porto Alegre, Salvador, Fortaleza) or with Infraero EPTAs, as in the cases of Guarulhos and Viracopos. 
The air navigation services providers are remunerated by the fees obtained by charging aircraft owners and operators for the use of communications and aid to Air Navigation. These tariffs are established in two types: (i) Rotated Air Navigation service (TAN); and (ii) TAT, which remunerates the TAT-APP and Aerodrome Control (TAT-ADR) Navigation Services in the Area of Approach Control.

Provisional Measure No. 866/2018, also published in the last days of the Michel Temer government, represents the option of creating a new air navigation state, due to the influence of the Aeronautics Command and the possible extinction of INFRAERO. This MP does not solve the organizational lack of definition of this important segment of Civil Aviation, still marked by militarism and the lack of clarity on the direction of an unprecedented arrangement in the world.

\section{New Brazilian Code of Aeronautics}

The Brazilian Code of Aeronautics in force (Law no. $7.565 / 86$ ) was enacted in 1986, prior to the Constitution (1988), the Consumer Protection Code (1990) and the law that created the ANAC (2005). On the initiative of the Federal Senate, at the end of 2015, a committee of experts was formed to formulate a proposal for the elaboration of a new Code. After many misunderstandings and confusions, the Commission's work was closed in 2016 with an extensive text. The 372 articles of the text address diverse subjects, ranging from civil aviation infrastructure, sector authorities, ANAC public consultation, foreign capital participation in the airships, ballooning, drone regulation, experimental aviation, sports flights, baggage, flight schools, transportation, user rights and civil liability [10].

The suggestions by the experts were transformed into Senate's project (PLS258 / 2016) and a special commission was formed by senators (CEAERO) to review the draft which has already received about 350 amendments. In a search made on February 20, 2019 on the website for the legislative process, the draft of the new code was yet to be approved by the Federal Senate to then go to the deliberation of the Chamber of Deputies [10].

In addition to the legislative slowness, part of the complexity in approving the new code is justified by several other factors that have compromised the project from the outset. There was not a good selection of experts for the mission, since among them were people who did not know the legislative process and ignored the basics of the relationship between politics, regulation, laws, legal hierarchy and technical attributions of the regulatory bodies. In addition, instead of adopting a perspective of modernization and simplification, they sought to create more bureaucratic and outdated mechanisms, including multiplying the duality of authorities in the sector.

In more developed countries, there is no aeronautical code, and authority in the sector tends to be unique; in Brazil, which already has two authorities, military aeronautics and civil aviation; with the eventual approval of this Project with the current conflicting drafting, the country would have two more authorities: the airport authority and the aeronautical investigation authority.

Before the new elected lawmakers approve a poorly crafted code that can inflate aeronautical regulation and generate legal insecurities, it may be more important to establish a new policy of deregulating, simplifying and strengthening of regulatory activity.

\section{Innovation and Aerospace Industry}

The issue of innovation deserves to be a priority in Brazilian civil aviation policy, basically for three reasons: for the national historical culture; for the current presence of a representative aeronautical industry in the world; and for the potential of making greater use of human resources and adding value to the productive chain in Brazil.

As for the cultural aspect, it arises from Santos-Dumont's national dream of taking off and using the invention of the aircraft for the progress of 
mankind. Brazil considers itself the home country of the inventor and has a history of dedication to the aviation industry which already has become part of the national culture, so Brazil cannot disregard this value in its future.

The aviation industry, due to its wide range of services and products, has contributed not only to the economy but also, indirectly, to the transfer of its innovations and quality standards to other national sectors. It is a segment with a wide range of products and services involved, such as: aircraft, satellites and launch vehicles, drones, defense equipment, all with considerable technological significance and fundamental components for Brazil on the road to development.

Brazil has already hosted several aeronautical component industries, but the most representative part of the current national aeronautical industry is Embraer. A state-owned company in 1969, it was privatized in 1994. And it is one of the three largest aircraft manufacturers in the world - after Boeing and Airbus.

Airbus recently joined the fourth largest aircraft manufacturer (Bombardier), a Canadian company which competes with Embraer in the aircraft market for regional aviation. Consequently, in a strategy for international competition and access to global markets, there has been an approximation between Boeing and Embraer. On July 5, 2017, both manufacturers signed a non-binding preliminary agreement, whereby the parties established the basic premises for a potential combination of certain businesses, which includes the creation of a joint venture at assessed value of US\$4.25 billion [11].

The proposal to set up a joint venture between the two manufacturers, in which Boeing would control $80 \%$ of the Brazilian manufacturer's commercial jets unit. Embraer's military plane and executive jet businesses were not part of the deal [11].

Even though Embraer is a private company, the Brazilian State is a shareholder with special power (Golden Share).Shortly after his inauguration in
January, President Jair Bolsonaro gave his approval for the deal. The agreement will now should be examined by antitrust authorities in Brazil and the US, where both companies have factories [11].

In addition to the historical perspective and the current representativeness of the Brazilian aviation, the new government should prioritize the innovation policy in the sector, so as to give greater opportunities for nationals to integrate, in a more dignified way, into the global production chain. Innovation, value added to the service chain, implementation of new techniques are some of the steps for the country to develop and go beyond the role of being a mere exporter of commodities or producer of low value added goods.

\section{Final Considerations}

It is hoped that the new Brazilian government will face the challenges of addressing the following issues: definition of the governmental structure of management of the sector, promotion of regional aviation, sustainability of airports, organization of the air navigation subsector, incentive and opening of the market for airlines, adaptation of the Brazilian Aeronautics Code, and aeronautics industry innovation and development policy. In addition to these challenges, other intra- and extra-sectoral problems should interfere with the dynamics of government referrals.

Given the degree of indebtedness of the Brazilian State, it is increasingly clear that the next Government should seek to do more with fewer resources. Brazil needs investments in the aviation sector and as these will not be predominantly state-owned, a more attractive structure should be created for foreign capital, giving legal security to the non-speculative investor. On the other hand, it is important to give more efficiency to state activity, be it the regulator or essential public service providers, subtracting institutional redundancies and better organizing air navigation services.

A deep reflection, discussions between professionals and academics, participation of stakeholders, serious 
planning, monitoring, implementation, transparency and supervision should be part of the new scenario. Civil aviation is one of the vectors for development and a means of regional integration that deserves to be well managed. Even if the Brazilian model has endured to the present, the question remains whether it is suitable at medium term, in a future perspective of integration and insertion in global competition.

\section{References}

[1] História do Controle do Espaço Aéreo Brasileiro. 2014. Rio de Janeiro, available online at: https://issuu.com/aeroespaco/docs/historia_controle_2edi cao/99.

[2] Tarcísio defende as concessões em seu $1^{\circ}$ discurso como ministro. News on the ministry's transport website, available online at:http://infraestrutura.gov.br.

[3] BRASIL, ANAC website. Information available online at: http://www.anac.gov.br/assuntos/paginas-tematicas/conce ssoes.

[4] INFRAERO website. Information available online at: http://www4.infraero.gov.br/acessoa-a-informacao/institu cional/relatorios-anuais/.

[5] BRASIL. Camara dos Deputados website. Information available online at: https://www2.camara.leg.br/.

[6] Em dez anos um país menos conectado. News from Jornal Oglobo, 30/04/2017 (Clauce Cavalcanti and Danielle Nogueira. Information avaliable at: http://www.oglobo.com.br.

[7] Havel, B. F., and Sanchez, G. S. 2014. The Principles and Practice of International Aviation Law. New York: Cambridge University Press (p.123-1530.

[8] BRASIL, ANAC website. Information available online at: http://www.anac.gov.br/A_Anac/internacional/acordos-in ternacionais/1111 acordos-de-servicos-aereos-1/1-1-3-aco rdo-multilateral-de-ceus-abertos-para-os-estados-membro s-da-comissao-latino-americana-de-aviacao-civil-clac.

[9] SILVA, F. C., and Ferreira, B. 2017. A Reestruturação dos Serviços de Navegação Aérea Brasileiros. Rio de Janeiro: SITRAER.

[10] BRASIL. Senado Federal website. Information available online at: http://www.senado.gov.br.

[11] EMBRAER website. Information available online at: https://embraer.com/br/pt/noticias. 